\title{
Function of miR-200a in proliferation and apoptosis of non-small cell lung cancer cells
}

\author{
YAN HUANG ${ }^{1}$, TING BAO $^{1}$, ZHENZHEN LI $^{1}$, GUIYI JI $^{1}$ and LI ZHANG $^{2}$ \\ ${ }^{1}$ Health Management Center and ${ }^{2}$ Laboratory of Pathology, West China Hospital of Sichuan University, \\ Chengdu, Sichuan 610041, P.R. China
}

Received March 13, 2018; Accepted September 21, 2018

DOI: $10.3892 / \mathrm{ol} .2020 .11649$

\begin{abstract}
Lung cancer is the most prevalent type of cancer worldwide and is the leading cause of cancer-associated cases of mortality in the USA and China. Non-small cell lung cancer (NSCLC) accounts for $80-85 \%$ of lung cancer cases. microRNAs (miRs) serve multiple roles in the pathogenesis of lung cancer. The current study investigated the lower level of miR-200a in tumor tissues compared with healthy tissue. Overexpression of miR-200a inhibited NSCLC cell proliferation and promoted apoptosis. miR-200a was identified to target Rhophilin Rho GTPase binding protein 2 (RHPN2) and higher levels of RHPN2 were observed in tumor tissues compared with adjacent normal tissues. The current study proposes that miR-200a exhibits a tumor suppressive role in NSCLC and suggests that miR-200a could target RHPN2.
\end{abstract}

\section{Introduction}

Lung cancer is the most prevalent cancer type worldwide $(1,2)$ and is the leading cause of cancer-associated cases of mortality in the USA and China (3). The American Cancer Society estimates that 159,260 Americans succumbed to lung cancer in 2014, which accounts for approximately $27 \%$ of all cancer-associated cases of mortality (4). In China, the estimated number of lung cancer-associated cases of mortality was 61,200 in 2015 (5). Despite vigorous efforts to prevent and treat this deadly disease, the 5-year survival rate of lung cancer $(16.6 \%)$ is lower than numerous other cancer types, including colon (64.2\%), breast (89.2\%) and prostate cancer $(99.2 \%)(4)$.

Non-small cell lung cancer (NSCLC) accounts for $80-85 \%$ of all cases of lung cancer (6). A number of patients with NSCLC are diagnosed at an advanced stage and curative surgical resection is only suitable for a limited number of cases (7). Overall,

Correspondence to: Dr Li Zhang, Laboratory of Pathology, West China Hospital of Sichuan University, 37 Guo Xue Xiang Road, Chengdu, Sichuan 610041, P.R. China

E-mail: jerrybb117@163.com

Key words: microRNA-200a, non-small cell lung cancer, proliferation, apoptosis, Rhophilin Rho GTPase binding protein 2 more than half of patients with NSCLC succumb to the disease within 1 year of being diagnosed (7). There is an urgent need to develop new strategies for treatment to lower the lung cancer mortality rate. MicroRNAs (miRNAs or miRs) serve multiple roles in the pathogenesis of lung cancer (8-14). MiR-200a, which belongs to the miR-200 family, is important for the initiation and invasion of tumors (15-20). A previous study has identified that miR-200a targets epidermal growth factor receptor and c-Met to inhibit migration, invasion and gefitinib resistance in NSCLC (19). Additionally, miR-200a may be a prognostic marker in metastatic NSCLC cells (20). However, the role of miR-200a in NSCLC is not fully understood.

The current study examined the expression of miR-200a in lung cancer tissues and assessed the function of miR-200a in NSCLC cells in vitro.

\section{Materials and methods}

Tissue samples. A total of 12 paired NSCLC and adjacent normal tissue samples were obtained from the Department of Pathology, West China Hospital of Sichuan University (Sichuan, China) between September 2014 and May 2016 (age range, 49-66 years; male:female ratio, 7:5). The use of human tissues was evaluated and approved by the Ethical Committee of Sichuan University. Written informed consent was obtained from all patients. All specimens were handled with no knowledge of the patients' identities, as legally required in China. The NSCLC tissue samples were evaluated and confirmed by a senior pathologist at the Sichuan University Cancer Center (Sichuan, China).

Cell culture. The NSCLC cell lines, H1703 and H2172, and the normal lung cell line, HEL299, were purchased from the Cell Bank of Sichuan University (Sichuan, China). Cells were cultured in Dulbecco's modified Eagle's medium (Thermo Fisher Scientific, Inc.) and supplemented with $10 \%$ fetal bovine serum (Thermo Fisher Scientific, Inc.). Cell were maintained at $37^{\circ} \mathrm{C}$ and $5 \% \mathrm{CO}_{2}$.

Immunohistochemical (IHC) analysis and point scoring system. A total of 12 paired NSCLC and adjacent normal tissue samples were processed using a standard protocol for IHC analysis. Briefly, the tissues were fixed in $10 \%$ neutral buffered formalin at room temperature for two days and 
embedded in paraffin. Four-micrometers thick sections were cut. For antigen retrieval, deparaffinization and hydration were performed. The slides were incubated overnight with anti-Rhophilin Rho GTPase binding protein 2 (RHPN2; catalog no. PA5-62469; 1:1,000; Thermo Fisher Scientific, Inc.) at room temperature. Following three washes with PBS, the slides were incubated with goat anti-rabbit IgG polyclonal horseradish peroxidase-conjugated secondary antibody (catalog no. 32260; Thermo Fisher Scientific Inc.; 1:1,000) at room temperature for $2 \mathrm{~h}$. The slides were developed by staining with diaminobenzidine (A600885; Sangon Biotech Co., Ltd.) and quantified manually (21). The slides were subsequently observed using a light microscope (Eclipse E100; Nikon Corporation; magnification, x200). IHC staining was scored according to the following criteria: $-(0-10 \%$ of the nucleated cells stained $) ;+(10-40 \%$ stained $) ;++(40-70 \%$ stained) and +++ (70-100\% stained).

Detection of miR-200a and RHPN2 by reverse transcription-quantitative polymerase chain reaction (RT-qPCR). Total RNA was extracted from the NSCLC tissue samples and cell lines using TRIzol reagent (Thermo Fisher Scientific, Inc.) according to the manufacturer's protocol. The level of miR-200a was measured using the Taqman miRNA RT-Real Time PCR kit (Thermo Fisher Scientific, Inc.) (22). qPCR was performed using the following primers: RHPN2 forward, 5'-AAGGGCTGTAA TCCCCTTGC-3' and reverse, 5'- CCGCACCTTTGAGTTTG TGG-3'; and GAPDH forward, 5'GAAGGTGAAGGTCGGA GTC-3' and reverse, 5'GAAGATGGTGATGGGATTTC-3'. The primer sequences were as following: miR-200c forward, 5'-CGTAATACTGCCGGGTAATGAT-3' and reverse, 5'-GTGTCGTGGAGTCGGCAA-3' and U6 forward, 5'-GCTTCGGCAGCACATATACTAAAAT-3' and reverse, 5'-CGCTTCACGAATTTGCGTGTCAT-3'. PCR thermocycling conditions for RHPN2 and GAPDH were as follows: $95^{\circ} \mathrm{C}$ for $10 \mathrm{~min} ; 42$ cycles at $95^{\circ} \mathrm{C}$ for $15 \mathrm{sec}$ and $60^{\circ} \mathrm{C}$ for $1 \mathrm{~min}$. PCR thermocycling conditions for miR-200a and U6 were as follows: 40 cycles of three-step PCR $\left(95^{\circ} \mathrm{C}\right.$ for $15 \mathrm{sec}, 55^{\circ} \mathrm{C}$ for $30 \mathrm{sec}$ and $72^{\circ} \mathrm{C}$ for $30 \mathrm{sec}$ ) following initial denaturation at $95^{\circ} \mathrm{C}$ for $10 \mathrm{~min}$. Quantification was performed using the $2^{-\Delta \Delta \mathrm{Cq}}$ method (23).

Prediction of the putative targets of miR-200a. TargetScan software (http://www.targetscan.org/) was used to predict the putative targets of miR-200a (24-26).

Cell proliferation assay. Cellular proliferation was analyzed by a MTT assay. Briefly, H1703 and H2172 cells were placed into 96-well plates at $5 \times 10^{3}$ cells/well. MTT reagent was added at a final concentration of $0.1 \mathrm{mg} / \mathrm{ml}$ with $100 \mu \mathrm{l}$ dimethyl sulfoxide at 24,48 and $72 \mathrm{~h}$. The optical density was measured on a microplate reader at a wavelength of $570 \mathrm{~nm} \mathrm{(27).}$

Cell apoptosis analysis. The cell apoptosis rate was analyzed using the Alexa Fluor 488 Annexin V/Dead Cell Apoptosis Kit (Thermo Fisher Scientific, Inc.). Briefly, cells $\left(5 \times 10^{5} / \mathrm{ml}\right)$ were suspended in Annexin V binding buffer (Thermo Fisher Scientific, Inc.) and stained with Annexin V-FITC and incubated for $15 \mathrm{~min}$ at room temperature. The cells were subsequently stained with propidium iodide (PI) at room temperature for 15 min (1:1,000; Thermo Fisher Scientific, Inc.). The samples were analyzed using a flow cytometer with a $488 \mathrm{~nm}$ excitation laser (argon-ion or solid state) and emission was detected at $530 \mathrm{~nm}$ (green; for FITC) and 575-610 nm (orange; for PI) with BD FACSuite software (version 1.0.4.2650; BD Biosciences).

Overexpression and downregulation of miR-200a in $\mathrm{H} 1703$ and H2172 cells. miR-200a expression levels in H1703 and $\mathrm{H} 2172$ cells were increased and decreased by transfection with a miR-200a mimic and miR-200a antisense oligonucleotide (ASO) (both from Aksomics; ArrayStar), respectively. Cells transfected with miR-negative control (NC) or miR-NC-ASO were used as controls. Prior to transfection, the cells were cultured overnight $\left(1 \times 10^{6} /\right.$ well $)$. Cell transfection was performed with Lipofectamine ${ }^{\mathrm{TM}} 2000$ (Invitrogen; Thermo Fisher Scientific, Inc.) according to the manufacturer's protocol. The sequences of the miR-200a mimic, the miR-200a AOS, the miR-NC and the miR-NC-ASO were as follows: miR-200a mimic, UAACACUGUCUGGUAACGAUGU; miR-200a ASO, ACAUCGUUACCAGACAGUGUUA; miR-NC, CAG AUUUUGUGUAGUACAA; and miR-NC-ASO, ACTGCCT GTCTGTGCCTGCTGT.

Western blot analysis. Cells were frozen and lysed in lysis buffer (150 mM NaCl, $50 \mathrm{mM}$ Tris-HCI, 1\% Triton X-100 and $0.1 \%$ sodium dodecyl sulfate) with a protease inhibitor cocktail (Sigma-Aldrich; Merck KGaA). The protein levels were determined by the bicinchoninic acid assay (28) and $30 \mu \mathrm{g}$ total protein/lane were separated via SDS-PAGE on a $10 \%$ gel (100 V for $2 \mathrm{~h}$ ). Proteins were subsequently transferred from the gel onto a methanol-activated polyvinylidene difluoride membrane. The membrane was blocked for $1 \mathrm{~h}$ at room temperature using 5\% milk. To detect RHPN2 protein, the membrane was incubated with anti-RHPN2 antibody (cat. no. ab23148; 1:1,000; Abcam) overnight at $4^{\circ} \mathrm{C}$. Following primary antibody incubation, the membrane was incubated a peroxidase-linked secondary antibody (1:2,000; cat. no. ab97120; Abcam) at room temperature for $2 \mathrm{~h}$. To detect $\beta$-actin protein, anti- $\beta$-actin antibody (1:1,000; cat. no. ab179467; Abcam) was used at a dilution of 1:1,000, followed by detection with a peroxidase-linked antibody to rabbit antibody $\operatorname{IgG}(1: 2,000$ dilution; cat. no. ab6747; Abcam). Proteins were detected with the ECL Western Blotting Detection reagents (GE Healthcare). Images were analyzed using ImageJ version 2 FX software (National Institutes of Health).

Dual-luciferase reporter assays. Cells were seeded at 1x105 per well and serum-starved for $6 \mathrm{~h}$ prior to transfection. An RHPN2 3'-untranslated region (3'UTR) mutant was generated using a site-directed mutagenesis kit (Promega Corporation). The mutated control was cloned and inserted into a pGL3-control vector (100 ng; Promega). The wild-type and the mutated 3'UTR of RHPN2 was cloned and inserted into a firefly luciferase reporter plasmid (pGL3 luciferase reporter vector; Promega Corporation). A miR-200a mimic and the reporter plasmid or the mutant 3'UTR plasmid (500 ng) were then co-transfected into H1703 cells with Lipofectamine ${ }^{\circledR} 2000$ (Invitrogen; Thermo Fisher Scientific, Inc.). Cells were harvested and luciferase activity was measured after $24 \mathrm{~h}$ using the Dual-Luciferase Reporter assay system (Sangon Biotech Co., Ltd.). 

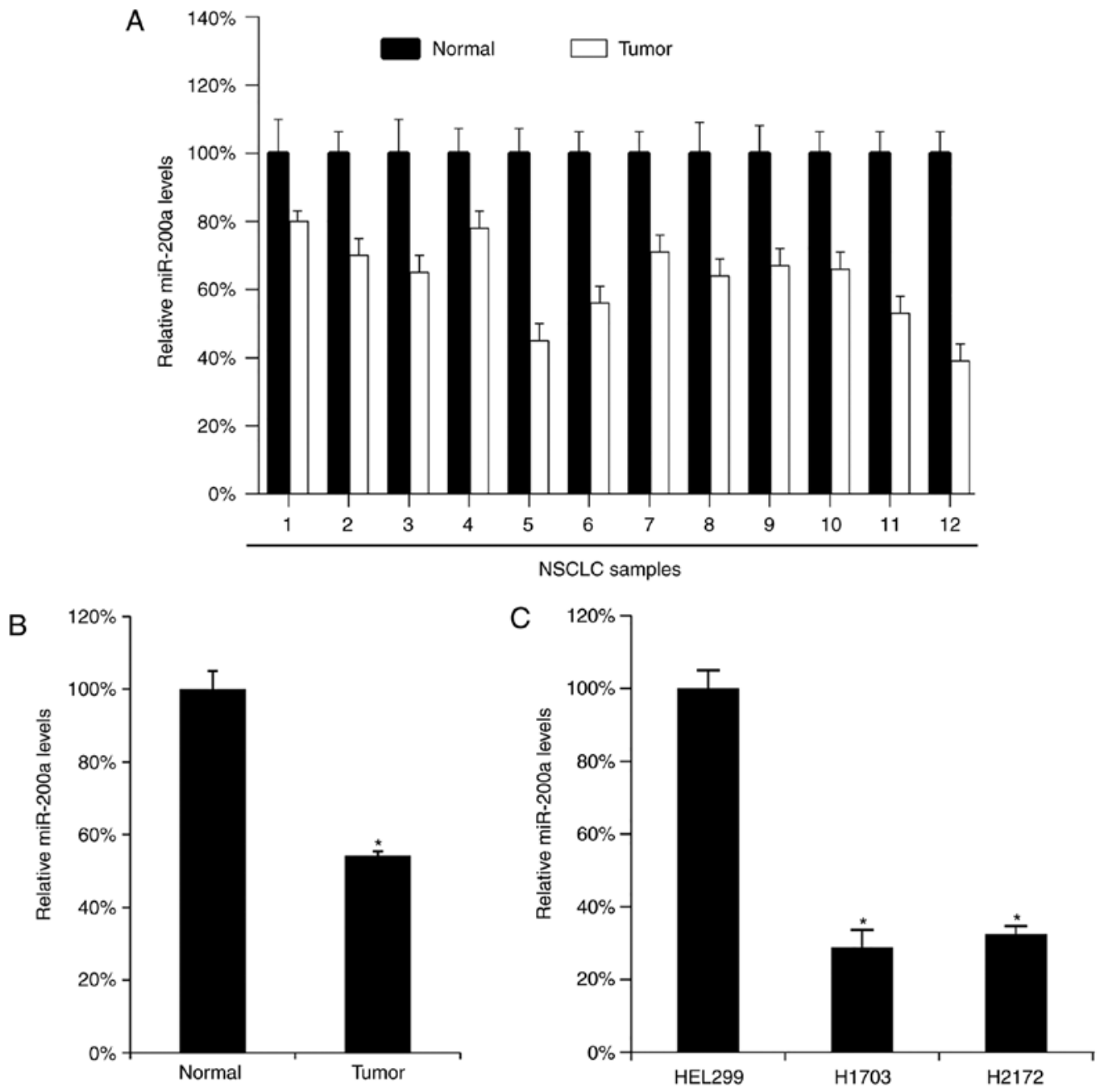

Figure 1. NSCLC tissue samples exhibit low levels of miR-200a. (A) A total of 12 paired NSCLC and adjacent normal tissue samples were collected from West China Hospital of Sichuan University. The miR-200a levels in the 12 paired NSCLC and adjacent normal tissue samples were analyzed by RT-qPCR. (B) The mean values of miR-200a expression in the 12 paired NSCLC and adjacent normal tissue samples were calculated. " $\mathrm{P}<0.05$ vs. Normal. (C) The miR-200a levels in a normal lung cell line (HEL299) and two NSCLC cell lines (H1703 and H2172) were analyzed by RT-qPCR. "P<0.05 vs. HEL299. The data are presented as the mean \pm standard deviation. Each experiment was repeated at least three times. RT-qPCR, reverse transcription-quantitative polymerase chain reaction; miR-200a, microRNA-200a; NSCLC, non-small cell lung cancer.

Statistical analysis. Data are presented as the mean \pm standard deviation from at least three independent experiments. A two-tailed Student's t-test was used to analyze the mean value between two groups. The difference between groups was analyzed using one-way analysis of variance with post hoc analysis by a Student-Newman-Keuls test, when three or more groups were compared. Correlation analysis was performed using two-tailed Pearson's correlation coefficient analysis. $\mathrm{P}<0.05$ was considered to indicate a statistically significant difference. All analysis was performed using SPSS software (version 16.0; SPSS, Inc.).

\section{Results}

miR-200a levels in lung cancer tissues. Initially, the current study measured miR-200a levels in 12 paired NSCLC and adjacent normal tissue samples by RT-qPCR. In all cases, the tumor tissue exhibited lower miR-200a levels compared with the matched-adjacent normal tissue (Fig. 1A). The mean values of miR-200a in the 12 paired NSCLC and adjacent normal tissue samples were calculated. Tumor tissue demonstrated a significantly lower mean level of miR-200a compared with healthy tissue (Fig. 1B). Similarly, a subsequent comparison revealed that the level of miR-200a was significantly lower in two NSCLC cell lines, H1703 and H2172, compared with a normal lung cell line, HEL299 (Fig. 1C).

In vitro role of miR-200a in NSCLC cell lines. As $\mathrm{H} 1703$ and $\mathrm{H} 2172$ cells demonstrated significantly lower levels of miR-200a, the current study regulated the miR-200a levels by transfection with miR-200a mimic and miR-200a ASO, which upregulate and downregulate miR-200a, respectively. As expected, transfection with the miR-200a mimic significantly increased the level of miR-200a in H1703 and H2172 cells, whereas miR-200a ASO transfection significantly decreased the level of miR-200a (Fig. 2A). Following transfection, cell growth was assessed. Upregulation of miR-200a inhibited cell growth, while downregulation of miR-200a significantly increased cell growth in H1703 and H2172 cells (Fig. 2B). Cell apoptosis was also investigated and it was identified that transfection with miR-200a mimic 


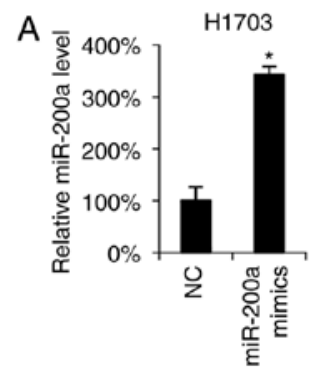

B

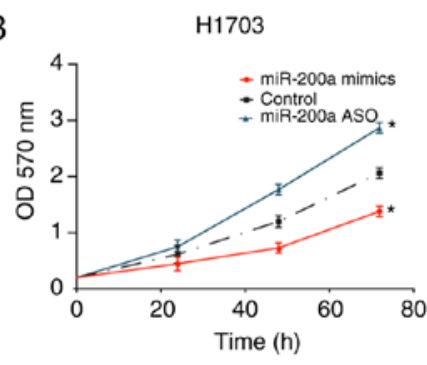

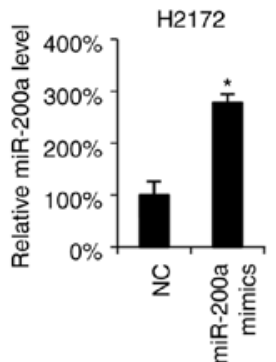

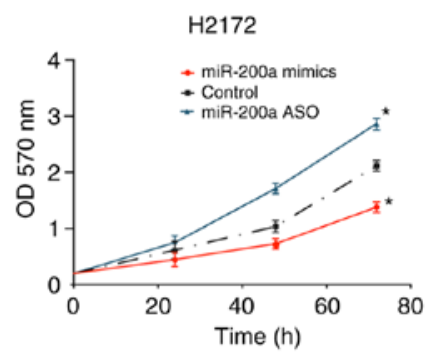

C

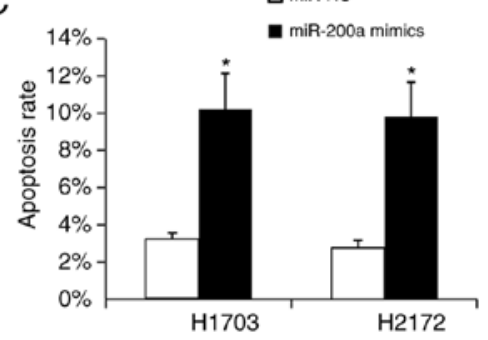

$\mathrm{H} 1703$

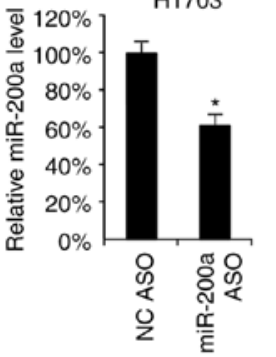

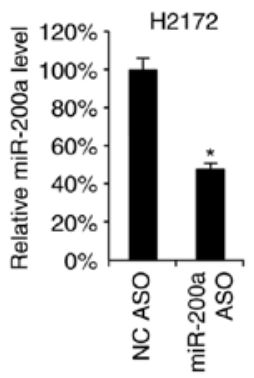
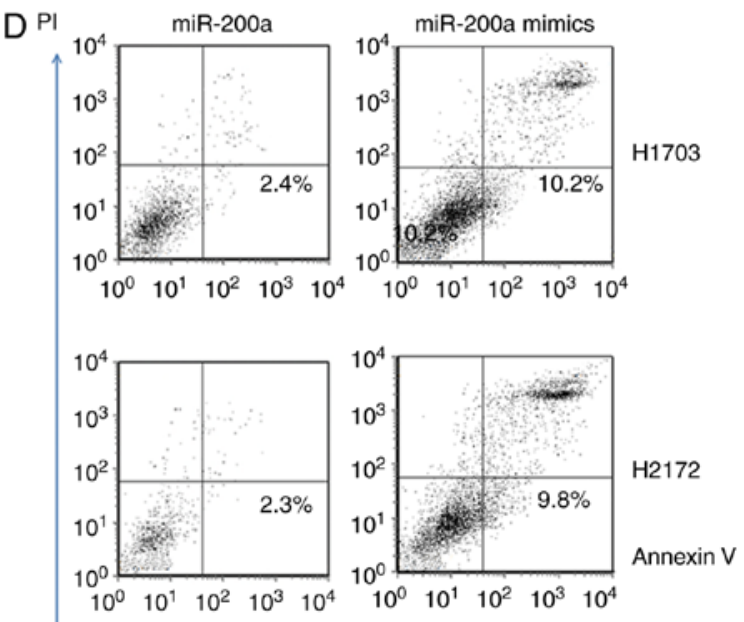

Figure 2. Overexpression of miR-200a inhibits H1703 and H2172 cell proliferation and promotes cells apoptosis. H1703 and H2172 cells were separately transfected with miR-200a mimic, NC, miR-200a ASO or NC ASO. (A) At 24 h transfection miR-200a expression was evaluated by reverse transcription-quantitative polymerase chain reaction. ${ }^{*} \mathrm{P}<0.05$ vs. NC or NC ASO. (B) Following transfection with miR-200a mimic and miR-200a ASO, the cellular proliferation of $\mathrm{H} 1703$ and $\mathrm{H} 2172$ was assessed by an MTT assay. ${ }^{*} \mathrm{P}<0.05$ vs. control. (C) At $48 \mathrm{~h}$ after transfection with miR-200a mimic, H1703 and $\mathrm{H} 2172$ cells were stained with Annexin V-FITC and PI, and the cell apoptosis rate was evaluated by flow cytometry. (D) The histogram of cell apoptosis rate. ${ }^{*} \mathrm{P}<0.05$ vs. miR-NC. miR-200a, microRNA-200a; NC, negative control; ASO, antisense oligonucleotide; OD, optical density; FITC, fluorescein isothiocyanate; PI, propidium iodide.

significantly increased the apoptosis rate in $\mathrm{H} 1703$ and $\mathrm{H} 2172$ cells (Fig. 2C and D).

RHPN2 is a target gene ofmiR-200a.RHPN2 encodes a member of the rhophilin family of Ras-homologous (Rho)-GTPase binding proteins and may be involved in the organization of the actin cytoskeleton (29). In malignant glioma, RHPN2 drives mesenchymal transformation (30). The current study identified that RHPN2 was a target gene of miR-200a. The binding sites of miR-200a in the 3'UTR of RHPN2 and the mutant 3'UTR of RHPN2 are presented in Fig. 3A. The two 3'UTRs were cloned into a luciferase reporter plasmid and a control plasmid. A miR-200a mimic and the reporter plasmid or control plasmid were co-transfected into H1703 cells. The activity of luciferase was assessed $12 \mathrm{~h}$ following transfection. The upregulation of miR-200a inhibited luciferase activity of the wild-type 3'UTR of RHPN2 but not the mutated version, indicating that miR-200a targets RHPN2 in H1703 cells (Fig. 3B). RHPN2 protein levels following transfection with the miR-200a mimic were determined. The transfection inhibited the RHPN2 protein levels in H1703 cells (Fig. 3C).

RHPN2 levels in NSCLC tissues. The protein level of RHPN2 was analyzed in the 12 paired NSCLC and adjacent normal tissue samples by IHC. The NSCLC tissue samples consistently demonstrated higher protein levels of RHPN2 compared with adjacent normal tissue. Representative paired NSCLC and adjacent normal tissue sample images are presented in Fig. 4A. The protein levels of RHPN2 were quantified using a point scoring system. All 12 NSCLC tissue samples scored a higher mean RHPN2 level compared with the adjacent normal tissue (Fig. 4B). Next, the RHPN2 mRNA levels were analyzed in the 12 paired NSCLC and adjacent normal tissue samples. Higher mean RHPN2 mRNA levels were consistently 
A Position 652-659 of RHPN2 3'UTR $5^{\prime} \ldots$ UUACUAACACAGUGGCAGUGUUA...

hsa-miR-200a $\quad 3^{\prime}$ UGUAGCAAUGGUCUGUCACAAL

Position 652-659 of RHPN2 $3^{\prime}$ UTR $\quad 5^{\prime}$...UUACUAACACAGUGGCAAAAAAA...

hsa-miR-200a $\quad 3^{\prime}$ UGUAGCAAUGGUCUGUCACAAU

B

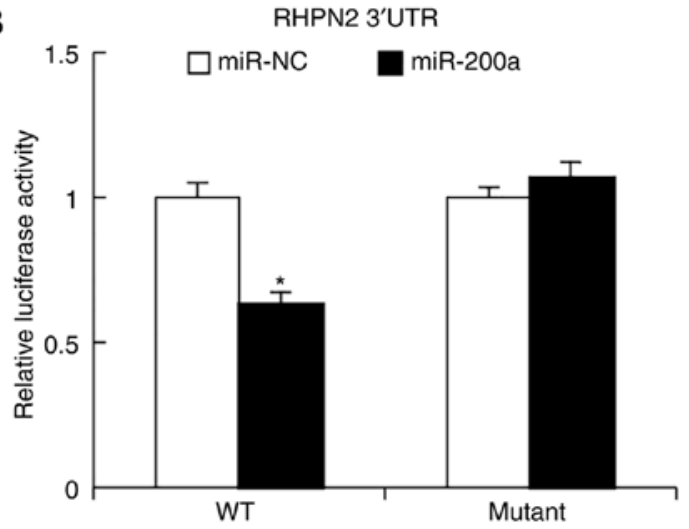

C

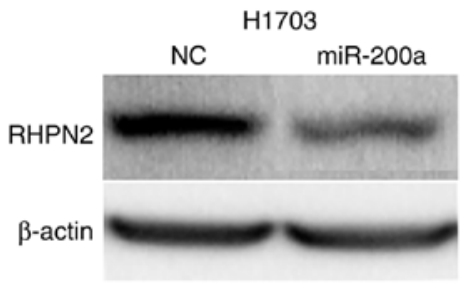

Figure 3. RHPN2 was identified as a target gene of miR-200a in H1703 cells. (A) The miR-200a binding site and its mutated version in the 3'UTR of RHPN2. (B) miR-200a mimic and a reporter plasmid containing the wild-type or mutated 3'UTR sequence of RHPN2 were transfected into H1703 cells and $48 \mathrm{~h}$ later the luciferase activity was analyzed. ${ }^{*} \mathrm{P}<0.05$ vs. miR-NC. (C) miR-200a mimic was transfected into H1703 cells and the abundance of RHPN2 protein was determined by western blotting. Each experiment was repeated at least three times. RHPN2, Rhophilin Rho GTPase binding protein 2; miR-200a, microRNA-200a; 3'UTR, 3' untranslated region; NC, negative control; WT, wild-type.

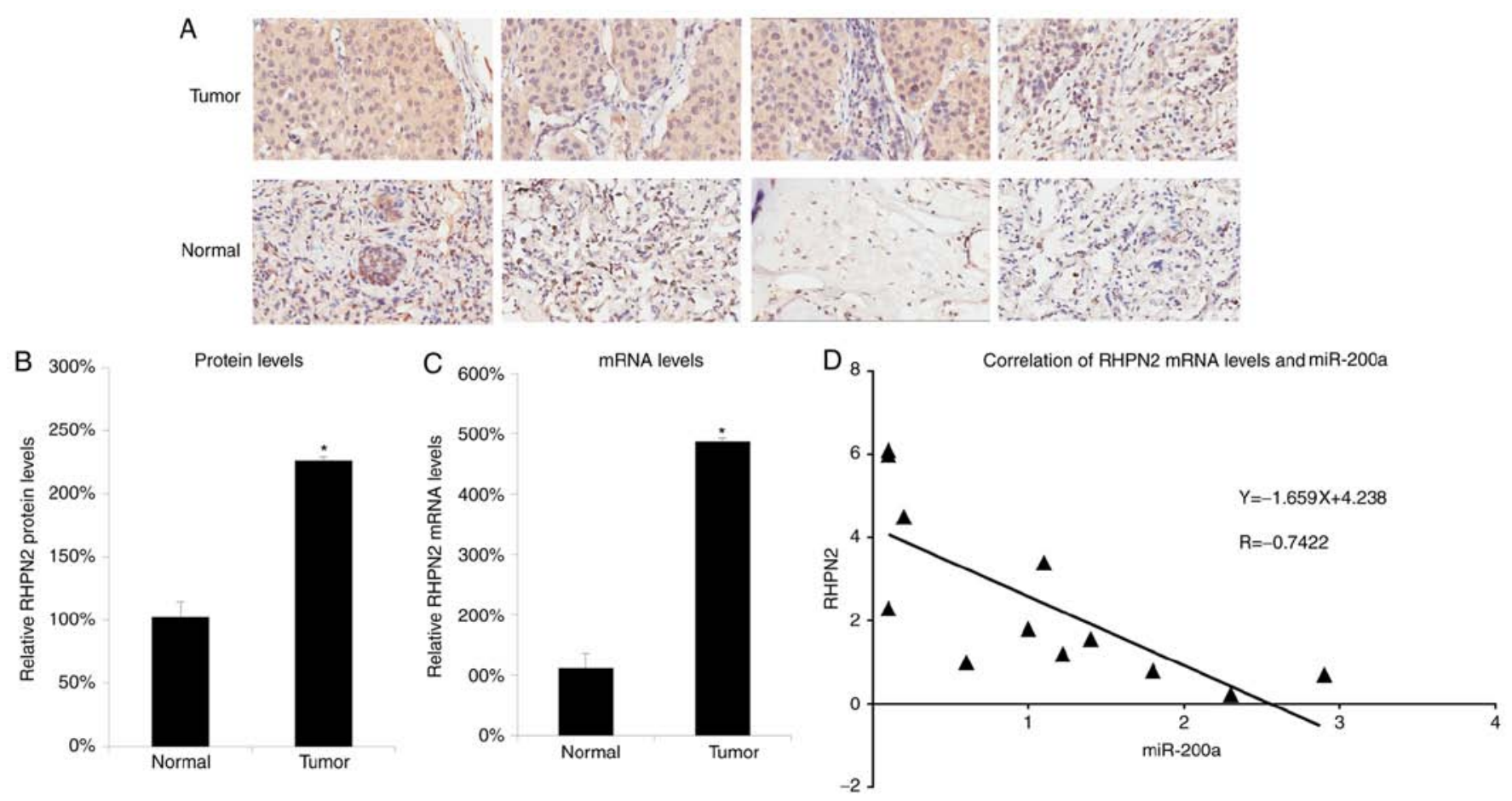

Figure 4. RHPN2 protein and mRNA levels in NSCLC tissue samples. A total of 12 paired NSCLC and adjacent normal tissue samples were collected for analysis of RHPN2 protein and mRNA levels. Tumor tissue samples and matched-adjacent normal tissue samples were processed by IHC for analysis of RHPN2 protein expression. (A) Representative figures of tumor and matched-adjacent normal tissues are presented. Magnification, x200. (B) IHC staining was scored according to the following criteria: - (0-10\% of the nucleated cells stained); + (10-40\% stained); ++ (40-70\% stained) and +++ (70-100\% stained). The mean expression of RHPN2 in NSCLC tissue samples was calculated relative to the mean expression of RHPN2 in normal tissue samples, which was arbitrarily defined as $100 \%$. (C) The RHPN2 mRNA levels in the 12 paired NSCLC and adjacent normal tissue samples were analyzed by RT-qPCR. The mean expression of RHPN2 mRNA in normal tissue samples was arbitrarily defined as 100\%. (D) RHPN2 mRNA and miR-200a levels in the 12 NSCLC tissue samples were analyzed by RT-qPCR. P $<0.05$. Correlation analysis was performed using two-tailed Pearson's correlation coefficient analysis. Each experiment was repeated at least three times. "P<0.05 vs. Normal. RHPN2, Rhophilin Rho GTPase binding protein 2; mRNA, messenger RNA; miR-200a, microRNA-200a; RT-qPCR, reverse transcription-quantitative polymerase chain reaction; NSCLC, non-small cell lung carcinoma; IHC, immunohistochemistry.

identified in the 12 NSCLC tissue samples compared with the matched tissue samples (Fig. 4C). In addition, RHPN2
mRNA expression levels were assayed in the 12 NSCLC tissue samples and correlation analysis was performed between 
RHPN2 mRNA expression and miR-200a expression. This analysis revealed a negative correlation between RHPN2 mRNA expression levels and miR-200a expression levels in the 12 NSCLC tissue samples (Fig. 4D).

\section{Discussion}

The role of miR-200a in NSCLC was investigated in the current study. NSCLC tissue samples demonstrated lower levels of miR-200a compared with matched normal lung tissues. In vitro experiments revealed that miR-200a inhibited growth of two NSCLC cell lines and promoted cell apoptosis. Furthermore, RHPN2 was identified as a target gene of miR-200a.

The miR-200 family are regulators of epithelial-mesenchymal transition (EMT) (31). E-cadherin repressors, zinc finger E-box binding homeobox (ZEB)1 and ZEB2, are target genes of the miR-200 family, serving a role in the EMT process (15). The current study revealed that miR-200a could target RHPN2. Previously, to the best of our knowledge, the function of RHPN2 in cancer has only been assessed in malignant glioma, in which it promotes mesenchymal transformation (30). The current study revealed that higher RHPN2 protein levels are expressed in NSCLC tissues compared with matched normal tissues. Furthermore, it was demonstrated that miR-200a could target RHPN2. The current data may be explained by two hypotheses. Firstly, RHPN2 may be a key factor in the EMT. Secondly, RHPN2 may participate in the EMT by regulating ZEB1 and ZEB2. The current study suggests miR-200a plays a role in the EMT process via RHPN2.

miR-200a, miR-141 and miR-429 belong to the miR-200 family (32). Previous studies have identified that miR-141 and miR-429 promote the proliferation of NSCLC cells $(33,34)$. However, the current study revealed that miR-200a inhibited growth of two NSCLC cell lines and promoted cell apoptosis. miR-141 regulates $\mathrm{PH}$ domain leucine-rich-repeats protein phosphatase 1 (PHLPP1) and PHLPP2, and miR-492 regulates deleted in liver cancer 1 (DLC-1), a tumor suppressor in NSCLC (34). Therefore, it can be proposed that miR-200a regulates RHPN2.

The current study only collected 12 paired NSCLC and adjacent normal tissue samples. Regardless, the results suggested that miR-200a serves an anti-tumor role in NSCLC via the targeting of RHPN2. Lower levels of miR-200a in NSCLC tissues compared with healthy tissues may be associated with the survival rate of patients with NSCLC. Future studies may investigate the prognostic value of miR-200a in NSCLC.

\section{Acknowledgements}

The authors would like to thank Dr Tao Huang (Department of oncology, West China Hospital of Sichuan University, Chengdu, China) for his helpful discussion of the article.

\section{Funding}

The current study was supported by the National Key R\&D Program of China (grant no. 2017YFC0907501).

\section{Availability of data and materials}

The datasets used and/or analyzed during the current study are available from the corresponding author on reasonable request.

\section{Authors' contributions}

LZ designed the study. YH and TB collected patient data and performed the cell experiments. ZL and GJ performed the molecular biology experiments. LZ wrote the manuscript. All authors read and approved the final manuscript.

\section{Ethics approval and consent to participate}

The present study was approved by The Ethics Committee of Sichuan University and all patients provided written informed consent.

\section{Patient consent for publication}

Not applicable.

\section{Competing interests}

The authors declare that they have no competing interests.

\section{References}

1. Jemal A, Siegel R, Ward E, Hao Y, Xu J, Murray T and Thun MJ: Cancer statistics, 2008. CA Cancer J Clin 58: 71-96, 2008.

2. Jemal A, Murray T, Ward E, Samuels A, Tiwari RC, Ghafoor A, Feuer EJ and Thun MJ: Cancer statistics, 2005. CA Cancer J Clin 55: 10-30, 2005.

3. Wen $\mathrm{C}$ and Dehnel T: China wrestles with lung cancer. Lancet Oncol 12: 15, 2011.

4. Siegel RL, Miller KD and Jemal A: Cancer statistics, 2016. CA Cancer J Clin 66: 7-30, 2016.

5. Chen W, Zheng R, Baade PD, Zhang S, Zeng H, Bray F, Jemal A, Yu XQ and He J: Cancer statistics in China, 2015. CA Cancer J Clin 66: 115-132, 2016.

6. Zappa C and Mousa SA: Non-small cell lung cancer: Current treatment and future advances. Transl Lung Cancer Res 5: 288-300, 2016.

7. Scheff RJ and Schneider BJ: Non-small-cell lung cancer: treatment of late stage disease: chemotherapeutics and new frontiers. Semin Intervent Radiol 30: 191-198, 2013.

8. Fabbri M, Garzon R, Cimmino A, Liu Z, Zanesi N, Callegari E, Liu S, Alder H, Costinean S, Fernandez-Cymering C, et al: MicroRNA-29 family reverts aberrant methylation in lung cancer by targeting DNA methyltransferases 3A and 3B. Proc Natl Acad Sci USA 104: 15805-15810, 2007.

9. Esquela-Kerscher A, Trang P, Wiggins JF, Patrawala L, Cheng A, Ford L, Weidhaas JB, Brown D, Bader AG and Slack FJ: The let-7 microRNA reduces tumor growth in mouse models of lung cancer. Cell Cycle 7: 759-764, 2008.

10. Chin LJ, Ratner E, Leng S, Zhai R, Nallur S, Babar I, Muller RU, Straka E, Su L, Burki EA, et al: A SNP in a let-7 microRNA complementary site in the KRAS 3' untranslated region increases non-small cell lung cancer risk. Cancer Res 68: 8535-8540, 2008.

11. Wiggins JF, Ruffino L, Kelnar K, Omotola M, Patrawala L, Brown D and Bader AG: Development of a lung cancer therapeutic based on the tumor suppressor microRNA-34. Cancer Res 70: 5923-5930, 2010.

12. Markou A, Tsaroucha EG, Kaklamanis L, Fotinou M, Georgoulias V and Lianidou ES: Prognostic value of mature microRNA-21 and microRNA-205 overexpression in non-small cell lung cancer by quantitative real-time RT-PCR. Clin Chem 54: 1696-1704, 2008. 
13. Zhang JG, Wang JJ, Zhao F, Liu Q, Jiang $\mathrm{K}$ and Yang GH: MicroRNA-21 (miR-21) represses tumor suppressor PTEN and promotes growth and invasion in non-small cell lung cancer (NSCLC). Clin Chim Acta 411: 846-852, 2010.

14. Volinia S, Calin GA, Liu C-G, Ambs S, Cimmino A, Petrocca F, Visone R, Iorio M, Roldo C, Ferracin M, et al: A microRNA expression signature of human solid tumors defines cancer gene targets. Proc Natl Acad Sci USA 103: 2257-2261, 2006.

15. Park S-M, Gaur AB, Lengyel E and Peter ME: The miR-200 family determines the epithelial phenotype of cancer cells by targeting the E-cadherin repressors ZEB1 and ZEB2. Genes Dev 22: 894-907, 2008

16. Korpal M,Lee ES, Hu G and Kang Y: The miR-200 family inhibits epithelial-mesenchymal transition and cancer cell migration by direct targeting of E-cadherin transcriptional repressors ZEB1 and ZEB2. J Biol Chem 283: 14910-14914, 2008.

17. Burk U, Schubert J, Wellner U, Schmalhofer O, Vincan E, Spaderna S and Brabletz T: A reciprocal repression between ZEB1 and members of the miR-200 family promotes EMT and invasion in cancer cells. EMBO Rep 9: 582-589, 2008.

18. Gregory PA, Bert AG, Paterson EL, Barry SC, Tsykin A, Farshid G, Vadas MA, Khew-Goodall Y and Goodall GJ: The miR-200 family and miR-205 regulate epithelial to mesenchymal transition by targeting ZEB1 and SIP1. Nat Cell Biol 10: 593-601, 2008.

19. Zhen Q, Liu J, Gao L, Liu J, Wang R, Chu W, Zhang Y, Tan G, Zhao X and Lv B: MicroRNA-200a Targets EGFR and c-Met to inhibit migration, invasion, and gefitinib resistance in non-small cell lung cancer. Cytogenet Genome Res 146: 1-8, 2015.

20. Pacurari M, Addison JB, Bondalapati N, Wan YW, Luo D, Qian Y, Castranova V, Ivanov AV and Guo NL: The microRNA-200 family targets multiple non-small cell lung cancer prognostic markers in H1299 cells and BEAS-2B cells. Int J Oncol 43: 548-560, 2013.

21. Angelucci A, Clascá F and Sur M: Anterograde axonal tracing with the subunit B of cholera toxin: A highly sensitive immunohistochemical protocol for revealing fine axonal morphology in adult and neonatal brains. J Neurosci Methods 65: 101-112, 1996

22. Schmittgen TD, Lee EJ, Jiang J, Sarkar A, Yang L, Elton TS and Chen C: Real-time PCR quantification of precursor and mature microRNA. Methods 44: 31-38, 2008.

23. Livak KJ and Schmittgen TD: Analysis of relative gene expression data using real-time quantitative PCR and the $2^{-\Delta \Delta C T}$ method. Methods 25: 402-408, 2001.
24. Agarwal V, Bell GW, Nam JW and Bartel DP: Predicting effective microRNA target sites in mammalian mRNAs. Elife: Aug 12, 2015 (Epub ahead of print). doi: 10.7554/eLife.05005.

25. Friedman RC, Farh KK, Burge CB and Bartel DP: Most mammalian mRNAs are conserved targets of microRNAs. Genome Res 19: 92-105, 2009.

26. Grimson A, Farh KK, Johnston WK, Garrett-Engele P, Lim LP and Bartel DP: MicroRNA targeting specificity in mammals: Determinants beyond seed pairing. Mol Cell 27: 91-105, 2007.

27. Denizot F and Lang R: Rapid colorimetric assay for cell growth and survival. Modifications to the tetrazolium dye procedure giving improved sensitivity and reliability. J Immunol Methods 89: 271-277, 1986.

28. Walker JM (ed): The bicinchoninic acid (BCA) assay for protein quantitation. In: The Protein Protocols Handbook. Springer, New York, NY, pp11-15, 2009.

29. Peck JW, Oberst M, Bouker KB, Bowden E and Burbelo PD: The RhoA-binding protein, rhophilin-2, regulates actin cytoskeleton organization. J Biol Chem 277: 43924-43932, 2002.

30. Danussi C, Akavia UD, Niola F, Jovic A, Lasorella A, Pe'er D and Iavarone A: RHPN2 drives mesenchymal transformation in malignant glioma by triggering RhoA activation. Cancer Res 73: 5140-5150, 2013

31. Korpal M and Kang Y: The emerging role of miR-200 family of microRNAs in epithelial-mesenchymal transition and cancer metastasis. RNA Biol 5: 115-119, 2008.

32. Humphries B and Yang C: The microRNA-200 family: Small molecules with novel roles in cancer development, progression and therapy. Oncotarget 6: 6472-6498, 2015.

33. Mei Z, He Y, Feng J, Shi J, Du Y, Qian L, Huang Q and Jie Z: MicroRNA-141 promotes the proliferation of non-small cell lung cancer cells by regulating expression of PHLPP1 and PHLPP2. FEBS Lett 588: 3055-3061, 2014.

34. Xiao P, Liu W and Zhou H: miR-429 promotes the proliferation of non-small cell lung cancer cells via targeting DLC-1. Oncol Lett 12: 2163-2168, 2016.

This work is licensed under a Creative Commons Attribution-NonCommercial-NoDerivatives 4.0 International (CC BY-NC-ND 4.0) License. 